\title{
Dress and care of infants in health and illness
}

\author{
C EISER, C TOWN, AND J TRIPP
}

Health Behaviour Research Group, Department of Psychology, University of Exeter and Department of Paediatrics, Royal Devon and Exeter Hospital

SUMmaRY The mothers of 199 infants (mean age 36.7 days) were interviewed to determine how the infant was dressed and wrapped, and how the mother would deal with illness. These data were related to measures of the infant's toe and underarm temperatures and demographic information about the family. The data did not support the hypothesis that infants with particular types of clothing or bedding were at risk of overheating and shows that most mothers dress their infants appropriately. Mothers' ideas about management of illness were often inappropriate particularly in lower socioeducational groups.

While folklore dictates that infants should be well wrapped to prevent them getting colds, there have been recent suggestions that this practice may lead to increased incidences of overheating and fever. ${ }^{1}$ Fever in children is not generally associated with adverse consequences. Some links, however, between fever and encephalopathy ${ }^{2}$ and cot deaths ${ }^{3}$ have been reported. Bacon ${ }^{1}$ has further argued that the probability of overheating is compounded by fabrics and designs used in the manufacture of infant clothing. He notes that 'synthetic materials are less permeable to sweat, and all-enveloping suits, sleeping bags, or tightly swaddled blankets prevent any circulation of air'. The present study began as a small survey of how women clothe and wrap their infants. These data were correlated both with infants' temperatures and demographic information about the families.

It is also apparent that widespread ignorance exists among parents as to how to treat fever in an infant. Schmitt ${ }^{4}$ has shown that parents can become anxious about low grade fever $\left(38.9^{\circ} \mathrm{C}\right)$ and sometimes believe that medium grade fever $\left(40 \cdot 0^{\circ} \mathrm{C}\right)$ has serious neurological consequences. (In contrast, paediatricians only regard temperatures in excess of $41^{\circ} \mathrm{C}$ as critical. $)^{5} \mathrm{~A}$ common erroneous belief is that the way to treat fever is to keep the infant warm. ${ }^{1}$ The second aim of this study was to investigate mothers' knowledge of how to treat illness in general and fever in particular in their infants.

\section{Method}

Subjects. All women delivered of a live baby between 16 December 1983 and 28 January 1984 and resident within the Exeter Area Health Authority were included in the study. At the interview, the infants were aged between 3 and 6 weeks (mean 36.7 days). In practice, $71.1 \%$ of the total sample took part $(n=199)$. Due to the large geographical area covered by the sample, $39(13.9 \%)$ were unable to be interviewed before the infant reached 6 weeks of age. A further $37(13.2 \%)$ were not at home on two separate visits by interviewers. Only six $(2 \cdot 1 \%)$ women who were approached actually refused to be interviewed.

All the infants included were single births. Birthweight ranged from 1445 to $5184 \mathrm{~g}$ (mean $3114 \cdot 2 \mathrm{~g}$ ). At birth, $78.4 \%$ of the sample were described by their mothers as 'very well'. Some $15 \cdot 6 \%$ of the sample had 'slight' problems (jaundice or sticky eyes). Four per cent of infants were admitted to the special care unit for less than one week, $1 \%$ for more than one week, and a further $1 \%$ were still attending hospiicu'! regularly.

The mean age of the inínts' mothers was 27.2 years (range 16 to 40 years). These women had completed full time education at a mean age of 16.9 years (range 14 to 25 years). The mean age of fathers was 30.7 years (range 19 to 51 years); these men had completed full time education at a mean age of 17.2 years (range $=14$ to 27 years). Social class of the sample was determined by father's occupation whether or not the couple were married. According to the Registrar General's classification the distribution was as follows; social class $I=6.5 \%$; II $=24.6 \%$; IIINM $=18.6 \%$; IIIM $=27.1 \%$, IV and $\mathrm{V}=10.6 \%$, Services $=3.0 \%$, Students $=1.0 \%$, and Unemployed $=8.5 \%$. These figures differ slightly from the 1981 census for the Exeter Health 
District, ${ }^{6}$ particularly in the under representation of social classes IV and V. The figures obtained in this census were as follows; $\mathrm{SCI}=6.1 \%$; II= $30.4 \%$, IIINM $=12 \cdot 4 \%$, IIIM $=31 \cdot 3 \%$, IV $=13.3 \%$, $\mathrm{V}=3.4 \%$, and Services $=3.0 \%$. A possible reason for this finding may be the slightly different methods used in the census tables for dealing with the unemployed category, since these are reported separately in our data but not in the census. Of the mothers, $94.5 \%$ described themselves to be generally in good health, as were $91.0 \%$ of the fathers.

Procedure. Mothers were interviewed by a female psychologist in their own homes. The first section of the questionnaire asked for details of how the infant was dressed (a) during the day (outside), (b) during the day (inside), and (c) during the night. We asked mothers to describe what the infant wore, and the materials from which these clothes were made. We also asked mothers about the number and type of blankets used to cover the child. If mothers were unsure of the type of material, the interviewer checked manufacturers' labels. Mothers were also asked if they swaddled the infant and how they checked for themselves if the infant was too hot or cold.

The second part of the questionnaire was concerned with mothers' beliefs about the causes of colds and their knowledge of the appropriate treatment for a number of conditions in infants which are likely to cause concern. Mothers were asked what they believed to be the reason for infants, school aged children, and adults getting colds. They were also asked how they would treat the following conditions in a young infant; a cold with high temperature, diarrhoea, a rash, and convulsions. (Many mothers did not know what a convulsion was. In these cases, the interviewer briefly described a convulsion.)

Interviewers then asked if they could take the infant's temperature. In eight cases where the infant was asleep, mothers asked that they should not be disturbed. Temperatures were taken using LifeWatch model LT-8 monitors (Albury Instruments). These give temperature readings using a thermometer probe (accuracy $\pm 02^{\circ} \mathrm{C}$ ). Readings were obtained under the infant's arm and at the great toe. A standard room thermometer was used to measure the temperature of the room the infant was in. The Metereological Office provided information about air temperature.

\section{Results}

How mothers clothe and wrap their infants. We analysed separately the type of clothing mothers reported their infants wore during the day (outside), during the day (inside), and at night. The main distinction we found was between infants generally dressed in 'babygros' and those dressed in separate garments. This latter category included nighties, dresses, and knitted suits. The results are summarised in Table 1 . It can be seen that most infants wore babygros most of the time. Furthermore, $99.0 \%$ of these were made from a mixture of cotton and synthetic fibres; only one child was dressed in a hand knitted babygro. The range of materials used in the manufacture of separate garments was greater. Eight of the nighties worn by 11 of the infants were made from brushed cotton or wynceyette, and three were of nylon fabrics. Dresses and knitted suits were made from wool (12) or acrylic (15) fabrics.

Mothers were also asked if they swaddled the infant at all. Over half of the sample $(55.3 \%)$ were not swaddling the infant at the time. Of these, $33.2 \%$ had never swaddled since leaving hospital, and $22 \cdot 1 \%$ had stopped swaddling soon after arriving home. The rest of the mothers swaddled the infant during the day $(2 \cdot 5 \%)$, night $(10.6 \%)$, sometimes $(13 \cdot 1 \%)$, and both day and night $(17 \cdot 6 \%)$. (Data were missing for this response from two mothers.) Reasons mothers gave for swaddling included bad weather $(9 \%)$ or when the infant was unwell (1\%).

Most infants slept in a pram or carry cot $(81.4 \%$ by day and $53.8 \%$ by night). Other infants slept in moses baskets $(15 \cdot 6 \%$ by day and $27.6 \%$ by night) or cot $(1.5 \%$ by day and $15 \cdot 6 \%$ by night $)$. A small number of infants could not be classified in this way (three by day and four by night).

Most infants slept on a sheet (wynceyette $58.5 \%$, cotton $37.5 \%$, and other $0.5 \%$ ). A small number of infants $(2 \%)$ slept in a baby nest. Coverings used over infants were diverse. Over half the infants $(64.3 \%)$ were covered directly by blankets, that is there was no top sheet. Most infants $(61.3 \%)$ were covered with blankets rather than quilts. Blankets

Table 1 Type of clothing worn by infants on different occasions (\%)

\begin{tabular}{lllr}
\hline & $\begin{array}{l}\text { Day } \\
\text { (outside) }\end{array}$ & $\begin{array}{l}\text { Day } \\
\text { (inside) }\end{array}$ & Night \\
\hline Vest & $93 \cdot 5$ & $93 \cdot 5$ & $95 \cdot 5$ \\
Nighty & $5 \cdot 0$ & $5 \cdot 5$ & $22 \cdot 1$ \\
Knitted suit & $18 \cdot 1$ & $5 \cdot 0$ & $0 \cdot 0$ \\
Dress & $10 \cdot 1$ & $9 \cdot 5$ & $0 \cdot 0$ \\
Cardigan & $78 \cdot 4$ & $64 \cdot 8$ & $59 \cdot 8$ \\
Socks & $39 \cdot 7$ & $31 \cdot 7$ & $33 \cdot 7$ \\
Mitts & $46 \cdot 2$ & $4 \cdot 0$ & $7 \cdot 5$ \\
Hat & $79 \cdot 4$ & $4 \cdot 0$ & $5 \cdot 5$ \\
Babygro & $75 \cdot 4$ & $77 \cdot 4$ & $78 \cdot 4$ \\
\hline
\end{tabular}


used to cover infants tended to be fairly evenly distributed between cotton, synthetic, or wool, and between woven or cellular forms. Infants were covered with one to six layers of blankets.

Infant, room, and outside temperature. Three measures of infant temperature were used in the analyses:

(1) Toe temperatures ranged from $18 \cdot 0^{\circ} \mathrm{C}$ to $34 \cdot 2^{\circ} \mathrm{C}$ (mean $26 \cdot 3^{\circ} \mathrm{C}$ ).

(2) Underarm temperatures ranged from $32 \cdot 0^{\circ} \mathrm{C}$ to $38 \cdot 0^{\circ} \mathrm{C}$ (mean $35 \cdot 8^{\circ} \mathrm{C}$ ). There was a marginally significant correlation between these two measures $(r=0.11 \quad P<0.06)$.

(3) A third temperature measure was derived, being the difference between these two temperatures (tdiff). This measure ranged from $2 \cdot 0^{\circ} \mathrm{C}$ to $18 \cdot 0^{\circ} \mathrm{C}\left(\right.$ mean $\left.=9 \cdot 59^{\circ} \mathrm{C}\right)$.

A large difference in the third measure was taken to be indicative of a cooler infant, (since an infant conserving heat vasoconstricts the periphery) and a small difference was taken to be indicative of a warmer infant.

These temperatures were correlated with two measures of environment temperature:

(1) The room the infant was in (range $10 \cdot 0^{\circ} \mathrm{C}$ to $25 \cdot 0^{\circ} \mathrm{C}$, mean $17 \cdot 9^{\circ} \mathrm{C}$ ).

(2) Outside air temperature (range $0.8^{\circ} \mathrm{C}$ to $14 \cdot 0^{\circ} \mathrm{C}$, mean $7 \cdot 5^{\circ} \mathrm{C}$ ).

Correlations between infant and room temperatures. There was a positive correlation between toe and room temperatures $(\mathrm{r}=0.25, \mathrm{P}<0.001)$; underarm and room temperatures were not significantly correlated $(r=0.03$, NS). There was a negative correlation between tdiff and room temperature $(r=-0 \cdot 16$, $P<0.02)$, that is infants in warmer rooms had smaller differences between toe and underarm temperatures.

Correlations between infant and outside temperature. There was again a positive correlation between toe and outside temperature $(r=0.23, P<0.001)$. Underarm and outside temperatures were not significantly correlated $(r=0 \cdot 08, N S)$. There was a non-significant correlation between tdiff and outside temperature, but in the same direction as previously, that is tdiff was smaller on warmer days $(\mathrm{r}=-0 \cdot 10, \mathrm{P}=0 \cdot 08)$.

Finally, there was a positive correlation between room and outside temperature $(r=0.13, P<0.03)$, confirming that rooms were warmer on warmer days. Room heating was provided by fixed gas or electric fires in $40 \%$ of homes and by central heating boilers in a further $40 \%$. Nine per cent of homes used coal fires and $4 \%$ relied on calor gas or paraffin.

We then conducted a series of analyses to look at the relations between infants' underarm and toe temperatures and other variables. Analyses with tdiff are not presented in detail since in all cases they reflect results with toe temperatures, generally at a less significant level.

Demographic variables. In all analyses involving fathers' occupation, we excluded the categories of Services, Students, and Unemployed, since these groups were both small and also heterogeneous. There were no significant correlations between toe and underarm temperatures and fathers' occupation (rho $=-0.09$ and rho $=0.02$ respectively). There was, however, a significant correlation between room temperature and fathers' occupation (rho $=0.18$, $P<0.006)$ suggesting that those in lower social classes keep their infants in warmer rooms. In all analyses involving mothers' age on leaving school, three groups were created; (1) those leaving school at 16 years or below, (2) those leaving at 17 to 20 years, and (3) those leaving at 21 years or more. Infants' toe temperatures were inversely correlated with mothers' age on leaving school (rho $=-0.02$, $\mathbf{P}<0.02$ ). There was also a significant inverse relation between room temperature and mothers' age on leaving school (rho $=-0.12, \mathrm{P}<0.05)$. No other correlations approached significance.

Type of clothing. We looked for differences between infants who were dressed in babygros and those dressed in separate garments on several demographic variables. Neither fathers' occupation $($ rho $=-0 \cdot 07)$, nor mothers' age on leaving school $($ rho $=0.08)$ predicted how the child was dressed.

We then conducted separate $t$ tests on toe and underarm temperatures to look for differences depending on whether the infant was dressed in babygros or separate garments. There were no significant differences between toe temperatures for infants dressed in babygros or separate garments (means 26.0 and $27 \cdot 1, t=1 \cdot 74, P<0.08$ ). Infants in separate garments, however, had marginally higher underarm temperatures (means $36 \cdot 2$ and $35 \cdot 2$, $t=3 \cdot 39, \mathrm{P}<0 \cdot 001$ ).

Further analyses were conducted comparing the type of clothing worn by those infants with the most extreme toe temperatures. Of 29 infants (approximately 15\%) with the highest temperatures, six wore separate garments and 23 wore babygros. Of 29 infants with the lowest temperatures, two wore separate garments and 27 wore babygros. $\mathrm{A} \chi^{2}$ test on these data was not significant $\chi^{2}=0 \cdot 25$ ).

Two separate analyses of covariance were then 
conducted using the infants' toe and arm temperatures as the dependent variable and room temperature as the covariate. In both analyses, we considered the effect of the type of clothing (separate $v$ babygros) and the number of additional clothes the infant wore. (Four levels of additional clothes were defined: (a) vest only; (b) vest and cardigan; (c) vest, no cardigan and some other items; and finally (d) vest, cardigan, and other items, for example mitts or hat.) These analyses were conducted using data from 167 subjects, since 13 subjects did not wear vests and therefore did not fall into any of the four categories above, and some data were missing from the remaining 19 cases.

The results of the first analysis confirmed the previous findings that infants in colder rooms had lower toe temperatures, and the type of garment (separates or babygros) was not significantly associated with toe temperatures. The number of additional garments, however, was significantly related to infants' toe temperatures, such that infants with more additional garments had lower toe temperatures, (mean toe temperatures for infants at four levels of other clothing $27 \cdot 2^{\circ} \mathrm{C}, 26.5^{\circ} \mathrm{C}, 25 \cdot 8^{\circ} \mathrm{C}$, $24.9^{\circ} \mathrm{C}$ ). These findings held while controlling for room temperatures.

In the second analysis, it was found that infants in separate garments had higher underarm temperatures than those in babygros even when controlling for room temperatures (mean underarm temperature for infants in separates $36 \cdot 2^{\circ} \mathrm{C}$, babygros $\left.35.7^{\circ} \mathrm{C}, \mathrm{F}=5 \cdot 51, \mathrm{P}<0.05\right)$. The number of additional garments the infant wore made no difference to underarm temperatures.

Swaddling behaviour. There was no relation between whether the baby was swaddled or not and toe (means $=26 \cdot 3^{\circ} \mathrm{C}$ and $26 \cdot 2^{\circ} \mathrm{C}$ ) or underarm temperatures (means $35 \cdot 8^{\circ} \mathrm{C}$ and $35 \cdot 8^{\circ} \mathrm{C}$ ). Infants who were swaddled, however, were kept in rooms with lower temperatures than those who were not swaddled (means $17.4^{\circ} \mathrm{C}$ and $18.3^{\circ} \mathrm{C}, t=2.02$, $P<0 \cdot 05)$.

Beliefs about causes of colds in infants, school children, and adults. Mothers were asked what they believed to be the causes of infants, children, and adults getting colds. Responses could be categorised as follows:

(a) Germs in the air.

(b) Catch colds off other people.

(c) Being cold or wet.

(d) Neglect (not being properly fed or cared for).

(e) Other.

The frequencies with which mothers gave these reasons for different groups are shown in Table 2.
Table 2 Beliefs of mothers about causes of colds in adults, children, and babies (number of people mentioning specific cause for each age group are not mutually exclusive)

\begin{tabular}{llcr}
\hline & Adults & Children & Babies \\
\hline Germs & 48 & 48 & 51 \\
Caught from others & 81 & 134 & 108 \\
Temperature & 93 & 64 & 95 \\
Neglect & 23 & 8 & 4 \\
Other & 15 & 9 & 12 \\
\hline
\end{tabular}

For infants, the most popular reason was that infants get colds from other people. Almost half the sample felt that infants could get colds by being cold. We looked at the relation between the mothers' beliefs about why infants get colds and the infant's temperatures, hypothesising that mothers who believed that being cold led to symptoms of a cold would have warmer infants. In fact there are no significant relations between these beliefs and any of the measures of infant's temperatures or room temperature.

Mothers were also asked if they thought that infants became ill more often, less often, or the same amount as adults and children. Altogether $68.3 \%(n=136)$ stated that infants became ill less often. The reasons given included 'because they were breast fed' $(n=58)$, 'looked after better' $(n=69)$, 'because they were naturally immune' $(n=39)$, or because 'I've never seen an ill infant' $(n=4)$. A further $21 \cdot 1 \% \quad(n=40)$ of mothers stated that infants became ill more often than adults and children. Their reasons included the fact that infants had not been exposed to infection and built up any resistance $(n=20)$, and because they were small $(n=2)$. The remaining mothers gave no reasons for their response.

Mothers were also asked how they themselves checked whether the infant was too hot. The vast majority relied simply on feeling the infant $(50 \cdot 3 \%)$ or colour $(45 \cdot 2 \%)$. A total of $29.1 \%$ of the sample also mentioned the infant became irritable if too hot, and $34.7 \%$ that the infant was likely to sweat. Only $0.5 \%$ used their own feelings about whether it was too hot as a guide to the baby's temperature.

Mothers were less confident about how to tell when the infant was too cold; $13 \cdot 1 \%$ stating that this had never happened. Again, the most popular method was simply to feel the baby $(83.4 \%)$, while $18.6 \%$ relied on colour. Some $15.1 \%$ of mothers reported that the infant became irritable when too cold.

Treatment for illnesses in infants. Mothers were asked how they themselves would treat a number of conditions in their infant. They could give as many 
responses as they liked; for this reason the categories below are not mutually exclusive. Their responses were categorised as follows:

\section{Convulsions}

(a) Call the doctor immediately (91.1\%); after 24 hours $(3 \cdot 0 \%)$.

(b) Cool the infant $(21 \cdot 6 \%)$.

(c) Warm the infant $(2 \cdot 0 \%)$.

(d) Lay infant on the side and prevent choking (35.0\%).

(e) Don't know (22.8\%).

\section{Cold with high temperature}

(a) Call the doctor immediately (79.3\%); after 24 hours $(13 \cdot 6 \%)$.

(b) Cool the infant $(32 \cdot 7 \%)$.

(c) Warm the infant $(20 \cdot 1 \%)$.

(d) Give medication $(1 \cdot 5 \%)$.

(e) Other (including cuddle, put to sleep more often $(25 \cdot 1 \%)$.

(f) Don't know (4\%).

\section{Diarrhoea}

(a) Call the doctor immediately (47.5\%); after 24 hours $(36 \cdot 4 \%)$.

(b) Increase infants fluids $(27 \cdot 1 \%)$.

(c) Starve the infant $(22 \cdot 6 \%)$.

(d) Change mother's diet (for breast feeders) (6.5\%).

(e) Don't know (5.5\%).

\section{Rash}

(a) Call the doctor immediately $(41.1 \%)$; after 24 hours $(41 \cdot 4 \%)$.

(b) Cool the infant $(16 \cdot 6 \%)$.

(c) Change washing powder $(7 \cdot 5 \%)$.

(d) Change mother's diet (among breast feeders) $(1 \cdot 0 \%)$.

(e) Don't know (3.5\%).

Treatment for illness in relation to demographic variables. We conducted a series of $\chi^{2}$ tests to look at mothers' age on leaving school in relation to reported action in the case of illness. In the case of convulsions, the percentage of mothers stating that they did not know what action to take was greater among the less educated mothers (younger on leaving school) $\left(\chi^{2}=7.5, \mathrm{df}=2, \mathrm{P}<0.05\right)$. Of those mothers mentioning the importance of temperature in dealing with infants with a cold and high temperatures, more educated mothers were more likely to state that it was important to cool the infant rather than keep the infant warm $\left(\chi^{2}=9 \cdot 1, d f=2\right.$, $P<0.02)$. In the case of a rash, more educated women were more likely to state that the infant should be cooled $\left(\chi^{2}=7 \cdot 9, \mathrm{df}=2, \mathrm{p}<0 \cdot 02\right)$.

\section{Discussion}

Use of the skin temperature measurements of the infants studied was designed to provide some objective measurement of the infant's response to its thermal environment. It was envisaged that underarm temperatures would have a close relation to core temperature with a small standard deviation, and that the difference between core and peripheral temperature, as represented by tdiff, would be a measure of the infant's physiological response of heat loss or heat conservation. In the event, underarm temperature varied more widely than expected and was almost certainly considerably lower than core temperature (since it is an extremely unlikely hypothesis that the core temperature in these infants was close to $35 \cdot 8^{\circ} \mathrm{C}$ ). There was also considerable variability in toe temperature. It is likely that this variability in both measures reflects practical difficulties encountered in obtaining these measures in the home.

This survey nevertheless provides information as to how mothers care for their young infant. Infants of both sexes are commonly dressed in babygros rather than traditional garments. Roughly a third of the infants were swaddled either during the day or night, or both, and a further $13 \%$ were sometimes swaddled. At night most infants were covered with blankets rather than duvets and the use of baby nests for sleeping infants was extremely low $(2 \%)$. The mean absolute toe temperature was unaffected by whether the baby was dressed in a babygro or separate garments, that is neither group was significantly warmer than the other. An alternative way of looking at these data is to look at infants with toe temperatures at the extremes of the range, since these are infants exhibiting the maximum observed degrees of either heat conservation (cold toe temperatures) or heat loss (warm toe temperatures). Analysis of this method as shown in the results did not show a different distribution of infants according to whether they were wearing babygros or separate garments and thus does not support the hypothesis that infants wearing either type of garment were likely to be either too warm or too cold.

We thus found no evidence that the custom of dressing infants in babygros rather than traditional garments led to significant differences in infants physiological state of heat balance. Since most babygros contain synthetics, these fibres in themselves were not found to be responsible for any increase in body temperature. While this may be true for the healthy infants included in our sample, it 
is not possible to say how these garments will affect the temperature of an unwell infant.

The finding that underarm temperatures in babies dressed in separate garments were higher than in infants dressed in babygros is hard to explain, given the above data, since we would predict that underarm temperature would vary less than toe temperature. Differences in ventilation of the underarm area might be significant, however, and could neither be controlled for, nor measured. One hypothesis would be that infants dressed in babygros which fit more closely around the upper arm would be less likely to have skin apposition between the inner aspect of the upper arm and axilla, so that the skin temperature would be less close to body temperature than in babies where these parts were in apposition. These data may be of interest in relation to the common practice of measuring underarm temperature clinically as an approximation to core temperature. It may well be useful to validate underarm and rectal temperatures on the ward. We also obtained information about the quantity and type of covers used. There was great variability in the number of layers, type of fabric, and age and method of manufacture (handmade, or commercially produced) of these coverings. For this reason it was felt to be unrealistic to attempt to quantify the relative degree of warmth of individual layers.

Infants in colder rooms tended to be wearing more clothes, to be more often swaddled, and yet to have lower toe temperatures. These data suggest that mothers were both dressing their infants appropriately for the environmental temperature that they were in and also that they had not over dressed infants in response to a cooler environment. Further evidence for this is the fact that the more additional clothes that were on the infant, the cooler the toe temperature. Looking at the obverse hypothesis that infants in warm rooms might be over dressed, and looking at those infants with high toe temperatures, these occurred no more frequently in infants in warm environments.

While most mothers were apparently responsive to temperature regulation in the healthy infant, they seemed less competent in handling the unwell infant. For all the ailments studied, a high proportion of mothers stated that they would seek medical advice. Only a small number seemed knowledgeable about appropriate actions. Although we did not specify to mothers that we were interested in their knowledge of febrile convulsions, it was apparent that few women knew what a convulsion was or what action to take. Nevertheless, the fact that few mothers stated that they would cool the infant with a convulsion may be taken as some indication that they were not generally aware of the possibility of convulsions resulting from overheating. We found that the mothers' level of education was the single most important predictor of her knowing how to deal with illness in the infant. Of special relevance is the fact that less educated mothers were less likely to state that they would attempt to treat high temperature or a rash by cooling the infant. In addition, the infants of these mothers had higher toe temperatures than infants of more educated mothers, and kept their infants in warmer rooms. All these factors taken together may suggest that a group of infants are at risk in terms of potentially dangerous increases in temperature.

It would seem that informing women about how to treat illness in their infant is likely to be beneficial, both in reducing unnecessary general practitioner contact and increasing the quality of care of the child. Such an intervention, designed to teach mothers about how to deal specifically with fever, has been shown to be relatively successful by Casey et al. ${ }^{7}$ Information about how to measure the infant's temperature and manage fever led to an increase in appropriate general practitioner referral (that is contact with the general practitioner where the fever so required, and home management in less serious cases). The data in our study highlight the need for large scale education of women on how to treat illness in their infants and when it is appropriate to seek professional advice.

This work was supported by a grant from the Health Education Council, London. We are grateful to Jacqui Hunt, Nicole Jones, Heather Perry, and Mary Pritchard who helped with the interviews. Staff at the Community Unit, Dean Clarke House provided information about the sample, and $\mathrm{Dr} R$ Budd helped with the analysis. We also thank Mr D R Griffiths of the Metereological Office at Exeter Airport and Albury Instruments for supplying temperature monitors.

\section{References}

1 Bacon CJ. Overheating in infancy. Arch Dis Child 1983;58: 673-4.

2 Bacon CJ, Scott D, Jones D. Heatstroke in well-wrapped infants. Lancet, 1979;i:422-5.

3 Stanton AN, Scott DJ, Downham MAPS. Is overheating a factor in some unexpected infant deaths? Lancet 1980;ii:1054-7.

4 Schmitt BD. Fever phobia. Am J Dis Child 1980;134:176-81.

5 Steele RW, Fever. In: Shirley HC, ed. Pediatric therapy. St. Louis: CV Mosby, 1975.

6 Office of Population Censuses and Surveys. Small area statistics. OPCS. Census, 1981.

${ }^{7}$ Casey R, McMahon F, McCormich MC, Pasquariello PS, Zavod W, King FH. Fever therapy: an educational intervention for parents. Pediatrics 1984;73:600-5.

Correspondence to Dr C Eiser, Department of Psychology, University of Exeter, Washington Singer Laboratories, Exeter EX4 4QG.

Received 21 January 1985 